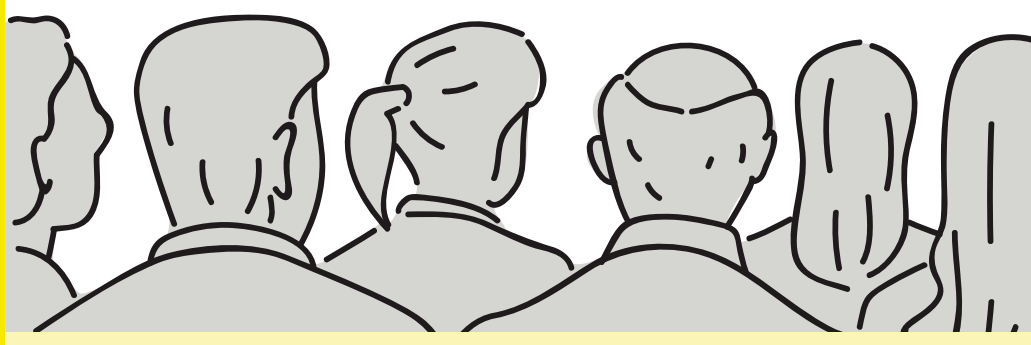

\section{NATIONAL DENTAL NURSING CONFERENCE PROGRAMME CONFIRMED}

The 2019 National Dental Nursing Conference, offering seven hours of enhanced CPD, will be held at the Oxford Spires Hotel, Oxford, on 1 and 2 November 2019. The Conference is open to all members of the dental team, but places are limited, so early booking is essential.

Conference will be opened by the Chief Dental Officer, England, Sara Hurley, who will give the Keynote Speech immediately after the inauguration of incoming BADN President Jacqui Elsden. After a buffet lunch, the lecture programme will start in the afternoon.

Friday's programme includes presentations on dental nurse apprenticeships by HEE's Mike Wheeler; on sedation by Janet Pickles of RA Medical; on dealing with difficult people by Max O'Neill; and the BADN AGM (current BADN members only); followed in the evening by an optional informal dinner (£35) in the hotel. Delegates are welcome to attend the dinner, or to go out into Oxford if they prefer.

Saturday's programme starts with a presentation by Rachael Whittaker on her experiences volunteering in Morocco with Dentaid; followed by a GDC Update by Colin McKenzie. After coffee, Simon Wright of the Institute of Clinical Excellence (ICE) will be speaking on human error factors. After lunch, forensic dentist Camilla George (pictured) will be talking about some of her cases and how dental nurses can get involved with forensics.

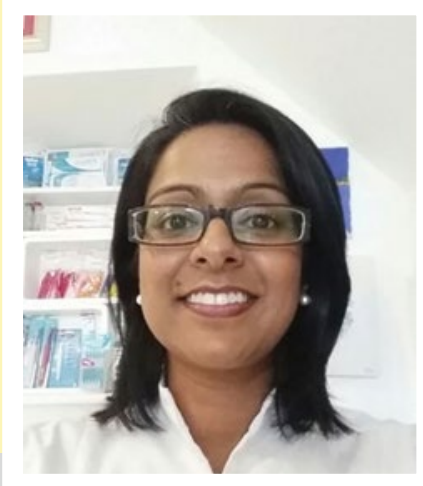

Camilla George, a forensic dentist who will be talking about some of her cases at the conference, and how dental nurses can get involved with forensics

At the Closing Ceremony, Jacqui will be highlighting delegates' achievements over the past year, presenting certificates, BADN Fellowships and the BADN Awards.

There is a special Conference rate for early bookings (by the end of September), plus discounts for current BADN and ONG members, and delegates can stay at the Oxford Spires Hotel at the special Conference rate, or in one of the many nearby hotels.

Places are limited, so to book yours now go to www.badn.org.uk and click on 'Events' at the top of the page. If you are not already a member of BADN - the UK's professional association for dental nurses - it is worth considering becoming one before booking your Conference place. Just go to www.badn.org.uk and click on the yellow 'Join Now' tab at the top of the page.
NATIONAL DENTAL NURSING CONFERENCE 2019 PROGRAMME

Friday 1 November 2019

0930-1045 Registration and Coffee

1100 Opening Ceremony, Keynote Speech and Presidential Inauguration

\section{Buffet Lunch}

1315 Apprenticeships - New Routes of Progression for the Dental Nurse Mike Wheeler, Programme Manager,

Dental Apprenticeships, Health Education England

1415 Sedation - The Digital Age

Janet Pickles, Chairwoman, RA Medical Services Ltd

1515 Coffee

1530 Dealing with Difficult People: Managing Patients, Teams and Bosses Max O'Neill, dental educator, Waterpik

1630 BADN AGM (members only)

1900 Informal dinner (optional)

Saturday 2 November 2019

0830-0915 Registration and Coffee

0930 Volunteering in Morocco with

Dentaid

Rachael Whitaker RDN

1030 GDC Update - including How the Balance is Shifting

Colin MacKenzie, GDC Head of Nations and Engagement

1130 Coffee

1145 Human Error Factors

Simon Wright, ICE

1245 Buffet Lunch

1400 The Role of the Dental Team in

Forensic Dentistry

Camilla George, Forensic Dentist 